\title{
Evaluation of Porous Structure of Cement Pastes Made with Residual Rice Husk Ash
}

João Henrique da Silva Rêgo ${ }^{1}$, Antônio Alberto Nepomuceno ${ }^{1}$, Enio Pazini Figueiredo ${ }^{2}$ and Nicole Pagan Hasparyk $^{3}$

1. Department of Environmental and Civil Engineering, University of Brasilia, Brasilia/DF 70910-900, Brazil

2. School of Civil Engeneering, Federal University of Goiás, Goiânia/GO 74605-22, Brazil

3. Department of Technical Support and Control, Furnas Centrais Elétricas, Aparecida de Goiânia/GO 74001-970, Brazil

\begin{abstract}
In several countries, the residual RHA (rice husk ash) has been produced in rice processing industries or in thermoelectric plants that use rice husk to generate heat and/or electrical energy, usually without burning process control. This causes a reduction in the amorphous silica content of residual RHA, which distinguishes them from the RHA produced according to controlled burning process, which is totally amorphous and considered a highly reactive pozzolan. In this paper, the hydration products and the porous structure of binders paste were studied by replacing, in weight of 5\%,10\% and 20\% of Portland cement OPC (ordinary Portland cement), by residual RHAs named A and B, which have high and low content of amorphous silica, respectively, using microstructure evaluation techniques as XRD (X-ray diffraction), TG (thermogravimetric) tests and MIP (mercury intrusion porosimetry). A reducing the size of the pores of the pastes was observed according to the increase of content replacement of RHA A and RHA B.
\end{abstract}

Key words: Mineral addition, residual rice husk ash, pozzolanic activity, porous structure, microstructure.

\section{Introduction}

The use of RHA (rice husk ash) as a mineral addition to cement is due to its high pozzolanic activity, originated from the high content of amorphous silica in its composition when obtained during a controlled burning process [1].

According to Refs. [2-5], considering that rice hush is used as biomass to produce heat and electricity in co-generation systems in different parts of the world, without burning process control, the study of the residual RHA properties becomes very important. Its characteristics differ from the RHA produced with the use of controlled burning. The reduction of the content of amorphous silica presented in the ash can be highlighted among these features.

Several studies have criticized the reasons that lead to discriminate the use of RHA residual as mineral

Corresponding author: João Henrique da Silva Rêgo, professor, research field: construction materials. E-mail: jhenriquerego@ig.com.br. addition [2-10]. The results of these authors demonstrate that, when finely divided, forming ultrafine ashes, there is possibility of using the residual RHA with low amorphous silica content as a mineral addition to replace part of Portland cement.

In this article, techniques as XRD (X-ray diffraction), TG (thermogravimetric) tests and MIP (mercury intrusion porosimetry) are used to identify and to analyze hydrating products and porous structure of seven pastes and mortars formed by the replacement in weight of OPC (ordinary Portland cement) (reference) for $5 \%, 10 \%$ and $20 \%$ of residual RHA A and RHA B which have, respectively, high and low contents of amorphous silica.

\section{Materials and Experimental Program}

\subsection{Materials}

The two studied RHAs were selected from the 10 samples obtained directly from producing companies of the residue in Brazil. Thus, according to the results 
of X-ray diffraction tests, it was possible to select the RHA A (most amorphous) and the RHA B (least amorphous) among the 10 samples. In this case, the objective was to select RHAs with high and low content of amorphous silica to identify their influence on the pozzolanic activity of RHA and on the porous structure of the cementitious material formed.

The grinding was performed in a ball mill specified for the Los Angeles abrasion test in coarse aggregates (ABNT NBR NM 51/2001) [11]. The RHA A and RHA B (2.5 kg) were milled, respectively, during $7 \mathrm{~h}$ and $6 \mathrm{~h}$ in the ball mills with a load of 40 steel balls with total weight of $10.50 \mathrm{~kg}$ in such a way that the RHAs reached medium diameter approximately equal and less than $10 \mu \mathrm{m}$.

The chemical characterization for RHAs and Portland cement were performed by an ED XRF (energy dispersive X-ray fluorescence) method and loss on ignition. The ED XRF data were obtained using a Shimadzu spectrometer (EDX-720) in high vacuum that analyzes the range of the elements sodium $\left({ }_{11} \mathrm{Na}\right)$ to uranium $\left({ }_{92} \mathrm{U}\right)$ with $\mathrm{X}$-ray tube of rhodium (Rh) target. The method, proposed by Paya et al. [12], was used to determine the amount of amorphous silica available of the RHA samples. The modified chapelle method, based on Ref. [13], is considered an eminently chemical method, in which the pozzolanicity of a material is determined by the amount of calcium oxide consumed by the pozzolan. For a material to be classified as pozzolanic, there is a minimum limit of $330 \mathrm{mg} \mathrm{CaO} / \mathrm{g}$. OPC without mineral additions (similar ASTM (American Society for Testing and Materials) Type I), obtained directly from a cement factory in a single batch, was employed as reference. The results of the characterization tests of RHAs and Portland cement are shown in Table 1. For the test of compressive strength standard, sand was used.

Attention is drawn to the fact that RHA A and RHA $\mathrm{B}$ are made up of nearly $87 \%$ and $89 \%$ of silica $\left(\mathrm{SiO}_{2}\right)$, respectively. The loss on ignition of RHA A samples, which determines the amount of unburned material, was $8.10 \%$, while on RHA B was $5.26 \%$. The content of amorphous silica in the RHA $\mathrm{A}$ is $81.30 \%$ and in the RHA $B$ is $17.66 \%$. The medium diameters of RHAs are practically the same, about $8 \mu \mathrm{m}$. Regarding the modified Chapelle method, RHA A and RHA B presented results that qualified them as pozzolans. Once this method is eminently chemical, it may be noted that the RHA B, with low amorphous silica contents, showed significant consumption of $\mathrm{Ca}(\mathrm{OH})_{2}$, indicating pozzolanic activity.

\subsection{Methods}

The compressive strength of OPC and compositions of binders with $5 \%, 10 \%, 20 \%$ of RHA A and RHA B

Table 1 Test results of characterization of RHA A, RHA B and OPC cement.

\begin{tabular}{|c|c|c|c|c|c|}
\hline \multicolumn{3}{|l|}{ Properties } & RHA A & RHA B & $\mathrm{OPC}$ \\
\hline \multicolumn{3}{|l|}{ Specific mass $\left(\mathrm{g} / \mathrm{cm}^{3}\right)$} & 2.12 & 2.22 & 3.10 \\
\hline \multicolumn{3}{|c|}{ Loss of ignition } & 8.10 & 5.26 & 1.63 \\
\hline \multicolumn{3}{|c|}{ Magnesium oxide $(\mathrm{MgO})$} & 0.41 & 0.40 & 4.24 \\
\hline \multicolumn{3}{|c|}{ Silicon dioxide $\left(\mathrm{SiO}_{2}\right)$} & 86.72 & 88.88 & 19.19 \\
\hline \multirow{6}{*}{ Chemical components $(\%)$} & \multicolumn{2}{|c|}{ Iron oxide $\left(\mathrm{Fe}_{2} \mathrm{O}_{3}\right)$} & 0.23 & 0.59 & 3.32 \\
\hline & \multicolumn{2}{|c|}{ Aluminum oxide $\left(\mathrm{Al}_{2} \mathrm{O}_{3}\right)$} & $<0.01$ & $<0.01$ & 4.42 \\
\hline & \multicolumn{2}{|c|}{ Calcium oxide $(\mathrm{CaO})$} & 0.70 & 1.05 & 60.60 \\
\hline & \multirow{3}{*}{ Total alkalis } & Sodium oxide $\left(\mathrm{Na}_{2} \mathrm{O}\right)$ & 0.13 & 0.08 & 0.30 \\
\hline & & Potassium oxide $\left(\mathrm{K}_{2} \mathrm{O}\right)$ & 1.27 & 1.38 & 0.88 \\
\hline & & Equiv. Alkaline & 0.97 & 0.99 & 0.88 \\
\hline Laser granulometry & \multicolumn{2}{|c|}{ Mean dimension $(\mu \mathrm{m})$} & 8.48 & 8.51 & - \\
\hline \multicolumn{3}{|c|}{ Amorphous silica content $(\%)$} & 81.30 & 17.66 & - \\
\hline \multicolumn{3}{|c|}{ Modified Chapelle (mg/g CaO) } & 657 & 450 & - \\
\hline
\end{tabular}


in 3, 7 and 28 days was determined in mortars through ABNT NBR 7215 [14]. For the pastes preparation of the seven binders with substitution, in weight, of OPC cement by RHA A and RHA B in different proportions $(5 \%, 10 \%, 20 \%)$ with relation $w /$ binder (water to binder ratio) $=0.50$, a $2 \mathrm{~L}$ planetary mixer was used. These levels of substitution were selected due to their usual replacement levels in several works $[2,6,9]$. Also according to a study by Ganesan et al. [15], replacement levels up to $30 \%$ are given as appropriate for the production of concrete with no negative effects on aspects of strength and durability when compared to pure cement.

The seven binders (cement OPC and RHA A or RHA B) were homogenized in a ceramic container. Then, the binders were mixed with water for $2 \mathrm{~min}$ at low rotation speed followed by $30 \mathrm{~s}$ of standstill and 2 min of mixing at high speed.

The $5 \times 10 \mathrm{~cm}$ cylinders were prepared in molds, covered with plastic wrap and immersed in water-saturated $\mathrm{Ca}(\mathrm{OH})_{2}$ until 91 days of hydration. The samples were removed from the inside of cylinders and the hydration reaction was paralyzed by immersing the samples in acetone for $30 \mathrm{~min}$ and drying them using an oven at $100{ }^{\circ} \mathrm{C}$ for $1 \mathrm{~h}$. When samples were prepared for X-ray diffraction and thermogravimetric tests, they were cracked with a hammer and then milled in a porcelain crucible. The $\mathrm{X}$-ray diffraction equipment used was Geigeflex T/Max RIGAKU diffractometer, operating with a copper tube and a nickel filter at $40 \mathrm{kV}$ and $20 \mathrm{~mA}$. Its scanning ranged from $2^{\circ}$ to $70^{\circ}$, speed in $2^{\circ}$ per minute. Thermogravimetric experiments were performed in an equipment of simultaneous thermal analysis DSC-TG, SDT 2960 model, TA instruments. As portable samples, an aluminum crucible and an aluminum oxide crucible were used as references for analysis. All thermogravimetric experiments were performed at a heating ratio of $20{ }^{\circ} \mathrm{C} / \mathrm{min}$, starting from room temperature (around $25{ }^{\circ} \mathrm{C}$ ) to $1,000{ }^{\circ} \mathrm{C}$ under continuous flux of $\mathrm{N}_{2}\left(110 \mathrm{~cm}^{3} / \mathrm{min}\right)$. The percentage of $\mathrm{Ca}(\mathrm{OH})_{2}$ was determined from the measured weight-loss curve between $425{ }^{\circ} \mathrm{C}$ and $550{ }^{\circ} \mathrm{C}$. The mercury intrusion porosimetry was performed using a Quanta Chrome PoreMaster mercury intrusion porosimeter assuming $0.485 \mathrm{~N} / \mathrm{m}$ and $130^{\circ}$ as the surface tension and the contact angle between mercury and pore wall, respectively. The samples of about 1 $\mathrm{cm}^{3}$ were cut out using a diamond cutter from the mid-portion of cylinders with $50 \mathrm{~mm}$ diameter and 100 $\mathrm{mm}$ height after 91 days of curing in the moisture controlled room and drying at $45{ }^{\circ} \mathrm{C}$ until constant mass.

\section{Results and Discussions}

\subsection{Compressive Strength}

The results of the compressive strength of the mortars of the seven binders at the age of 3, 7 and 28 days are shown in Fig. 1. It can be observed a gain of compressive strength at all ages with the substitution of the RHA A in relation to the reference mortar, reaching increases of up to $27.5 \%$ for $20 \%$ of replacement after 28 days. With the incorporation of $20 \%$ of RHA B, despite of a decrease of compressive strength at the age of 3 days compared to the reference mortar, occurred an increase of the compressive strength of approximately $10 \%$ at 28 days. The positive effect on the compressive strength of concrete was also observed by Cordeiro et al. [8] and Sensale [9].

According to Ref. [16], when dispersed in the paste, the small particles of pozzolans generate a large number of nucleation sites for precipitation of cement hydration products. Additionally, the microfiller effect (physical) of the finer grains ensures a denser packing within the cement paste and reduces the wall effect in the paste-aggregate transition zone. This behavior reinforces the effect of the pozzolanic reaction between the amorphous silica presented in the pozzolan and the calcium hydroxide produced by cement hydration reactions. These survey results demonstrate the existence of a hybrid action, combined 


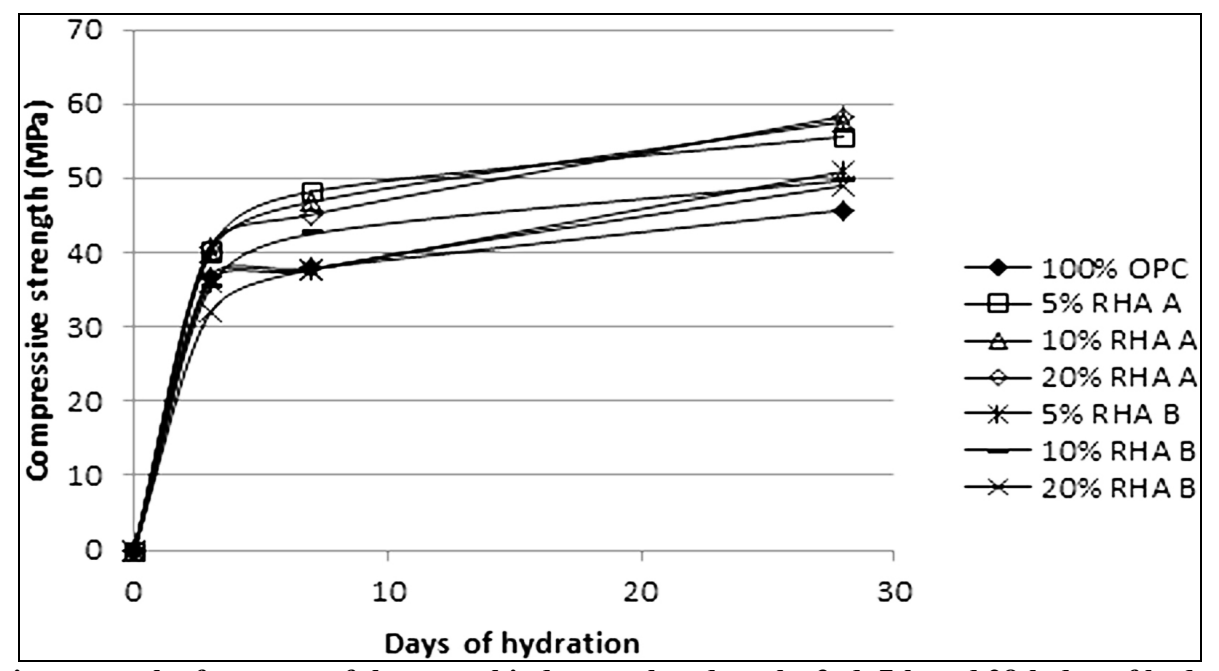

Fig. 1 Compressive strength of mortars of the seven binders analyzed on the 3rd, 7th and 28th day of hydration.

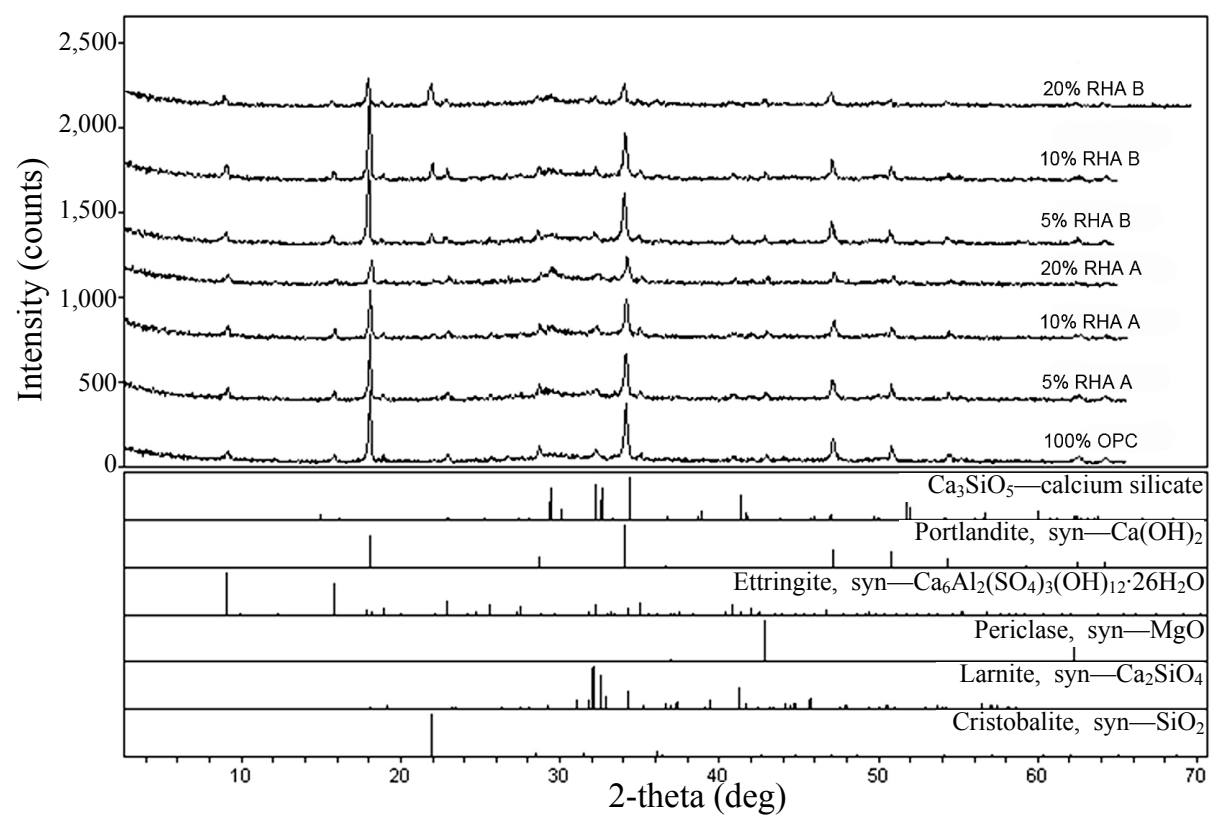

Fig. 2 X-ray diffractograms of pastes of seven binders analyzed with $w /$ binder relation $=0.50$ at 91 days of hydration.

and synergic among the effect of the Portland cement hydration, the pozzolanic reaction and, mainly, the microfiller effect (physical). According to Ref. [9], the increase of the compressive strength of concretes with the residual RHA can be explained mainly by the microfiller effect.

\subsection{X-Ray Diffraction}

The X-ray diffractograms of the seven binders paste with relation $w /$ binder $=0.50$ and age of 91 days of hydration are shown in Fig. 2. It was observed that the presence of portlandite in all seven binders pastes were analyzed. A decrease in the characteristic peaks of portlandite was observed in the X-ray patterns of pastes with the increase of the content of OPC cement replacement by RHAs A and B. It may be observed that an increase of the peak of cristobalite in pastes with the increase of the percentage of the cement replacement by RHA B.

\subsection{Thermogravimetric tests}

$\mathrm{CH}$ (calcium hidroxide) index was obtained by 
dividing the percentage of $\mathrm{Ca}(\mathrm{OH})_{2}$ of the paste of specific binder by the percentage of $\mathrm{Ca}(\mathrm{OH})_{2}$ of pastes with $100 \%$ OPC. The $\mathrm{CH}$ index values of the binders at 91 days of hydration are shown in Fig. 3. With concentrations of substitution of $20 \%$ of RHAs A and $\mathrm{B}$, the $\mathrm{CH}$ index reached values of $33.81 \%$ and $44.82 \%$, respectively. This behavior indicates the consumption of calcium hydroxide by the pozzolanic reaction of RHA A and RHA B.

\subsection{Mercury Intrusion Porosimetry}

In Fig. 4, it is possible to observe the results of total porosity (\%) and porosity of pores larger than $5 \times 10^{-2}$ $\mu \mathrm{m}(\%)$ in each of the seven pastes with $w /$ binder relation $=0.50$ at the age of 91 days of hydration. The total porosity of the pastes increases when there is growth of the Portland cement replacement by RHAs A and B. But at the same time, a refinement of the porous structure of the paste occurs during the increase replacement of OPC for RHAs. With $20 \%$ of RHAs A and B, only $1.67 \%$ and $3.71 \%$ of the volume of paste are composed of pores larger than $5 \times 10^{-2} \mu \mathrm{m}$, while for the paste with $100 \%$ OPC cement, it was observed that $12.86 \%$ of the volume of the paste presents larger pore size. In Fig. 5, it is observed with increasing of substitution of OPC by RHAs A and

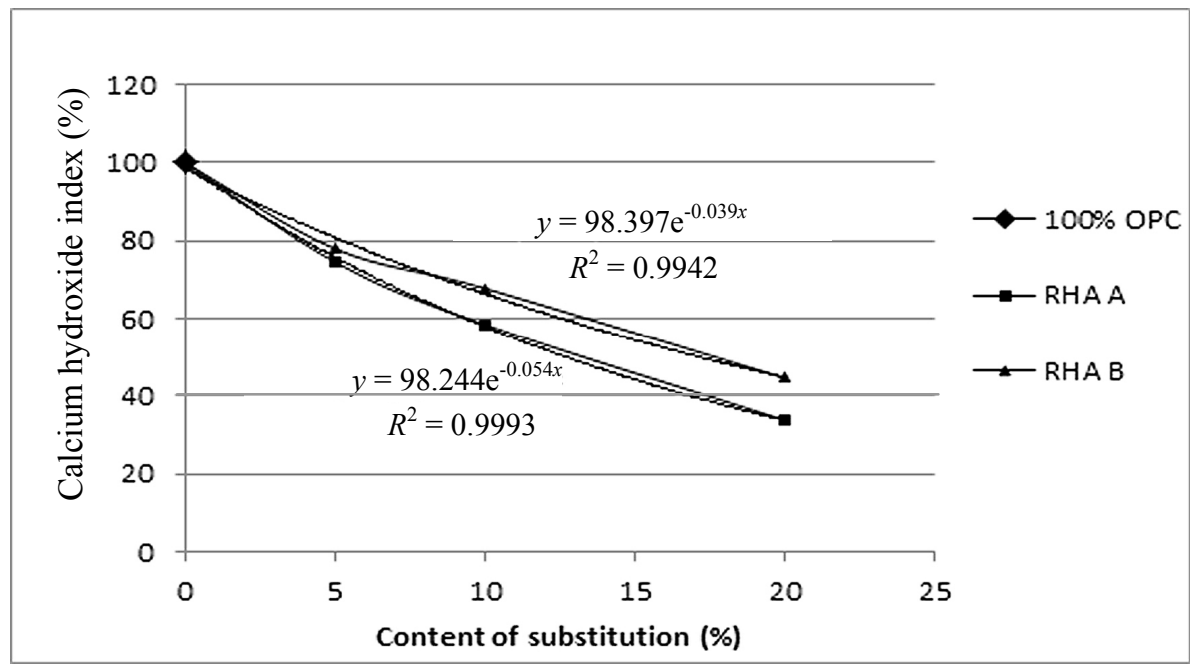

Fig. 3 Calcium hydroxide index (\%) in relation to the content of substitution of the RHAs A and B for the analyzed binders at 91 days of hydration.

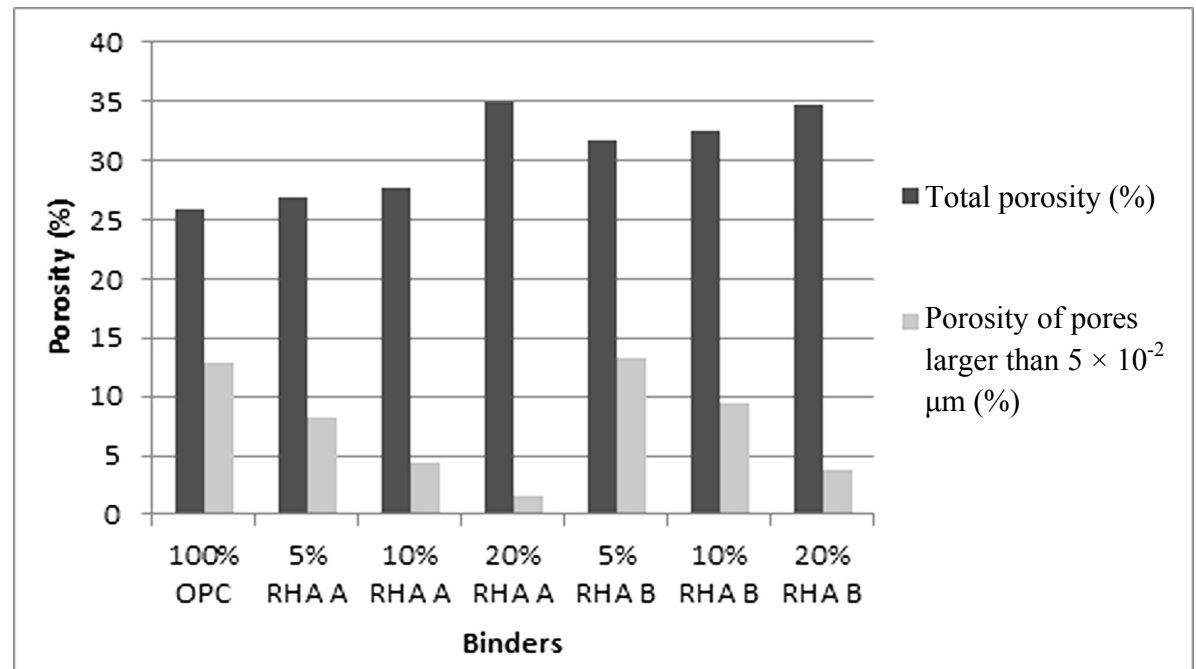

Fig. 4 Total porosity (\%) and porosity of pores larger than $5 \times 10^{-2} \mu \mathrm{m}(\%)$ in pastes with $w /$ binder relation $=0.50$ at 91 days of hydration. 


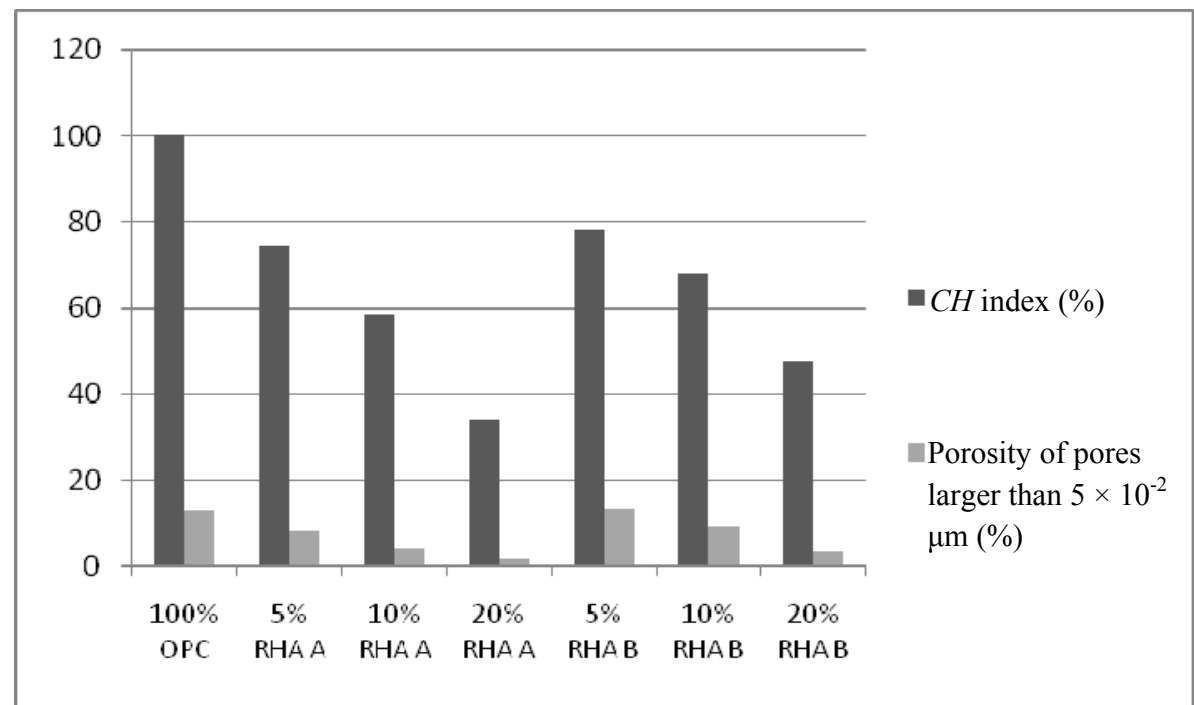

Fig. $5 \mathrm{CH}$ index $(\%)$ and porosity of pores larger than $5 \times 10^{-2} \mu \mathrm{m}(\%)$ in pastes with $w /$ binder relation $=0.50$ at 91 days of hydration.

$\mathrm{B}$ that there is reduction of $\mathrm{CH}$ index and a refinement of the pore structure of the pastes.

The refinement of porous structure of paste with substitution of OPC cement for RHAs A and B is probably due to synergy between activity effects of highly reactive pozzolans in the microstructure of the pastes: consumption of calcium hydroxide to form C-S-H (pozzolanic effect), pore filling by very thin pozzolans (microfiller effect) and increase of areas for growth of hydrating products (effect of nucleation sites) that act together, thus, reducing the size of paste pores and increasing durability of cementitious materials [10], confirm the effectiveness of the residual RHA in the durability of the concrete.

\section{Conclusions}

Based on experimental results, the following conclusions can be made:

(1) The RHAs A and B with low content of amorphous silica, when finely divided, showed pozzolanic behaviour. The tests (modified Chapelle, XRD and TG) confirmed the consumption of calcium hydroxide by both RHAs;

(2) With the MIP results, it can be observed that there is a significant refinement (reduction of pore size) of the porous structure with increase of substitution of OPC cement by RHAs A and B;

(3) Probably the refinement of the porous structure is due to the combined efforts of the pozzolanic reaction, microfiller effect and nucleation points of the RHAs in the microstructure of the paste. The improvement of durability of pastes with increases of levels of RHA A and RHA B is a result of the refinement of their porous structures, since only pores larger than $5 \times 10^{-2} \mu \mathrm{m}$ are responsible for entry of deleterious agents in the paste.

\section{Acknowledgments}

The authors wish to acknowledge to CAPES (Coordination of Improvement of Higher Education staff) for the support formalized as scholarships and research assistance, Furnas Central Eletric, for providing materials and equipaments for testing, and ANEEL (National Electric Energy Agency) for financial support.

\section{References}

[1] P.K. Mehta, K.J. Folliard, Rice husk ash-A unique supplementary cementing material, in: V.M. Malhotra (Ed.), Advances in Concrete Technology, Natural Resource, Ottawa, 1992, pp. 419-444.

[2] J.H.S. Rêgo, As cinzas de casca de arroz (CCAs) amorfas e cristalinas como adição mineral ao cimento-Aspectos 
da microestrutura das pastas (Amorphous and crystalline Rice husk ashes (RHAs) used as mineral admixtures to cement-Aspect of the paste microstructures), D.Sc. Thesis, University of Brasilia, Brazil, 2004. (in Portuguese)

[3] G.C. Cordeiro, R.D.T. Filho, L.M. Tavares, E.M.R. Fairbain, S. Hempel, Influence of particle size and specific surface area on the pozzolanic activity of residual rice husk ash, Cement and Concrete Composites 33 (5) (2011) 529-534.

[4] W. Xu, T.Y. Lo, S.A. Memon, Microstructure and reactivity of rice husk ash, Construction and Building Materials 29 (2012) 541-547.

[5] A. Muthadi, S. Kathandaraman, Optimum production conditions for reactive rice husk ash, Materials and Structures 43 (2010) 1303-1315.

[6] G.C. Isaia, Efeito de Misturas Binárias e Ternárias de Pozolanas em Concreto de Elevado Desempenho: Um estudo de Durabilidade com Vistas à Corrosão da Armadura (Effect of binary and ternary mixtures of Pozzolanas in Concrete High Performance: A Study of durability with Views in reinforcement corrosion), D.Sc. Thesis, Polytechnic University of São Paulo, 1995. (in Portuguese)

[7] G.C. Cordeiro, Utilização de cinzas ultrafinas do bagaço de cana-de-açúcar e da casca de arroz como aditivos minerais em concreto (Use of sugarcane bagasse and rice husk ashes as mineral admixture in concrete), D.Sc. Thesis, COPPE (Coordination of Programs Postgraduate Engineering)/Federal University of Rio de Janeiro, 2006. (in Portuguese)

[8] G.C. Cordeiro, R.D.F. Toledo, E.M.R. Fairban, Use of ultrafine rice husk ash with high-carbon content as pozzolan in high performance concrete, Materials and Structures 42 (7) (2009) 983-992.

[9] G.R. Sensale, Strength development of concrete with rice-husk ash, Cement \& Concrete Composites 28 (2006) 158-160.

[10] G.R. Sensale, Effect of rice-husk ash on durability of cementitious materials, Cement \& Concrete Composites 32 (2010) 718-725.

[11] ABNT (Associação Brasileira de Normas Técnicas), Small-Size Coarse Aggregate-Test Method for Resistance to Degradation by Los Angeles Machine, NBR NM 51, Rio de Janeiro, 2001.

[12] J. Paya, J. Monza, M.V. Borrachero, A. Mellade, L.M. Ordonez, Determination of amorphous silica in rice husk ash by a rapid analythical method, Cement and Concrete Research 31 (2001) 227-231.

[13] M. Raverdy, M. Brivot, A.M. Paillere, R. Bron, Appreciátion de l'activite pouzzolanique des constituants secondaires (Assessment of activity pozzolanic of the secondary constituents), in: 7th International Congress on the Chemistry of Cement, Paris, France, 1980, pp. 36-41. (in French)

[14] ABNT, Portland Cement-Determination of Compressive Strength-Test Method, NBR 7215, Rio de Janeiro, 1996.

[15] K. Ganesan, K. Rajagopal, K. Thangavel, Rice husk ash blended cement: Assessment of optimal level of replacement for strength and permeability properties of concrete, Construction and Building Materials 22 (2008) 1675-1683.

[16] G.C. Isaia, A.L.G. Gastaldini, R. Moraes, Physical and pozzolanic action of mineral additions on the mechanical strength of high-performance concrete, Cement and Concrete Composites 25 (2003) 69-76. 